\title{
Potential Outflow Pathways for Iberian Atmospheric Middle-Lived Pollution
}

\author{
R. Nieto ${ }^{1,2}$, R. Trigo ${ }^{2,3}$ and L. Gimeno ${ }^{* 1,2}$ \\ ${ }^{1}$ Universidad de Vigo. Facultad de Ciencias de Ourense. 32004. Ourense. Spain \\ ${ }^{2}$ University of Lisbon, CGUL-IDL, Lisboa, Portugal \\ ${ }^{3}$ Universidade Lusófona, Departamento de Engenharias, Lisbon, Portugal
}

\begin{abstract}
We present a study of the potential export pathways of middle-lived pollutants from the Iberian Peninsula using an advanced 3-D Lagrangian atmospheric transport model (FLEXPART). A period of five years, from 2000 to 2004, was analyzed. Results confirm that the Mediterranean Sea and Central Asia are the dominant sinks of the air originated in the Iberian Peninsula in the range of 3 to 10 days of transport. The study is important, both in scientific terms and in the preparation of useful information for decision-making.
\end{abstract}

Keywords: Sinks of middle-lived pollutants, sinks of aerosols, Lagrangian atmospheric transport model, Iberian Peninsula.

\section{INTRODUCTION}

There are a large number of atmospheric substances that can undergo long-range transport and have a far-reaching impact on the tropospheric composition, even thousands of kilometres downwind from their source region. This atmospheric transport occurs on timescales in the range of 3-10 days, being crucial for substances that have a lifetime span within this range (typically ozone $\left(\mathrm{O}_{3}\right)$ and its precursors, aerosols, mercury or persistent organic pollutants (POP)). In recent years, different works have explored the continental outflow of these middle-lived substances from North America [1-3]. These studies are usually based on the intensive use of 3-D transportation models, often associated with a chemistry component. Considering the entire Western Europe as a source, Duncan BN [3] concluded that the dominant export pathways in winter are characterised by the advection to middle/low latitudes of the North Atlantic Ocean while in the summer months the advection is observed predominantly to Russia and the Mediterranean Ba$\sin$ /northern Africa. The southward flow of European pollution in summer over the Mediterranean basin and Africa has been already described by Stohl A [4] using a Lagrangian approach similar to the one adopted here. Several studies have stressed the important role played by the synoptic-scale warm conveyor belts (WCBs), associated with frontal systems, in long-distance pollution transport, namely towards Europe [5-10]. However this WCBs mechanism plays a very limited role to lift European pollution due to the fact that these systems rarely originate near Europe.

Recent advanced Lagrangian atmospheric transport models enable us to establish, with good accuracy, sourcereceptor relationships over long distances up to 10 days of transport. Thus the main objective of the present study is to assess the export pathways for these middle-lived substances that have their origin over the Iberian Peninsula. This purpose will be achieved by using the successful 3-D Lagrangian particle dispersion model FLEXPART [11] coupled

*Address correspondence to this author at the Universidad de Vigo. Facultad de Ciencias de Ourense. 32004. Ourense. Spain;

E-mail:1.gimeno@uvigo.es with meteorological analysis data from the European Centre for Medium-Range Weather Forecasts (ECMWF) [12]. Despite FLEXPART quality and robustness it must be stressed that this methodology does not incorporate a specific chemistry component. Therefore this approach is particularly suited to assess the outflow (and inflow) pathways of air particles that correspond to middle-lived non-reactive gases and aerosols, and indirectly to assess their most likely sinks within the 10 day framework. The sink term will be used hereafter in a wider-than-usual context, in order to identify the regions where the air particles can be found, after travelling from Iberia for a given number of days. This study complements the previous work undertaken by Nieto and Gimeno [13] where the authors have evaluated the potential sources of these middle lived substances reaching the Iberian Peninsula.

\section{METHOD}

As in $[11,13]$ the atmosphere was 'filled' homogeneously with a large number of so-called "particles", each representing a fraction of the total atmospheric mass. Afterwards these particles are transported by the FLEXPART model using three-dimensional winds, with their positions being recorded every six hours. In this study tracks of 1,398,801 particles were used over a five-year period (2000-2004). We tracked trajectories forwards from an area covering the entire Iberian Peninsula (Fig. 1), limiting the transport time length to 10 days. Full details of the FLEXPART model can be found in $[14,15]$, while a brief summary on the most relevant details used in a similar application can be seen in [13]. In this analysis the FLEXPART model computed ECMWF operational analysis every six hours (at $00,06,12$, and 18 UTC) with a $1^{\circ} \mathrm{x} 1^{\circ}$ resolution on 60 vertical levels. The level density is higher at lower levels, with approximately 14 model levels below $1500 \mathrm{~m}$ and "only" 9 levels between $1500 \mathrm{~m}$ and $5000 \mathrm{~m}$.

\section{RESULTS}

We tracked forward in time the air masses residing in the entire vertical column located above the Iberian Peninsula area. Fig. (2) shows the number of particles residing over a 


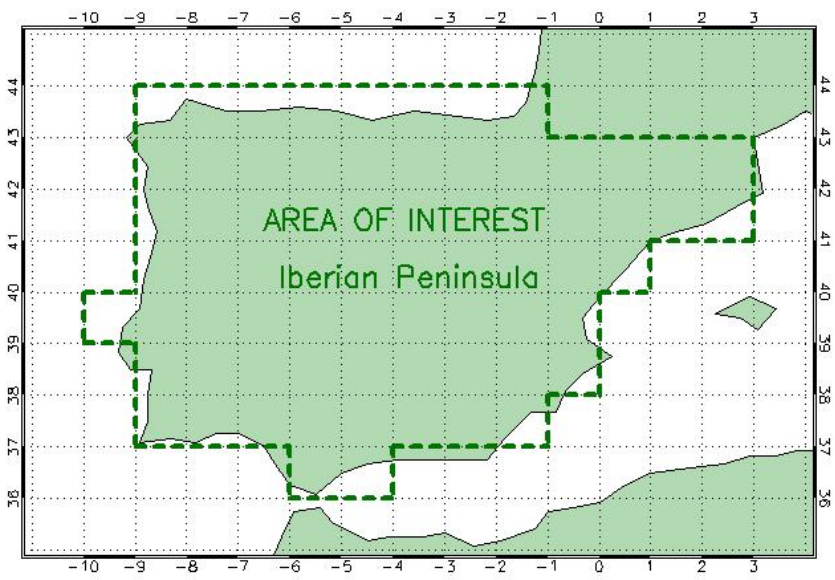

Fig. (1). Map of the source region considered in this work; the Iberian Peninsula. The dashed line shows the limits of the geometrical polygonal figure used based on the $1^{\circ}$ resolution grid cells from the ECMWF.

place (sinks) on the third, sixth, and tenth days of transport for the whole five-year period considered (Jan 1, 2000 until December 31, 2004). The last panel presents the sink location averaged between day three and day ten. This period is in the range of the typical time-span of middle-lived particles in the atmosphere, such as mercury or aerosols. The lifetime of elemental mercury is around 10 days in the more restrictive studies between $60^{\circ} \mathrm{N}$ and the equator [16], but the generally accepted atmospheric residence time for mercury is one year or more. In the case of aerosols, those between 0.02 $\mu \mathrm{m}$ and $0.1 \mu \mathrm{m}$ and residing above the planetary boundary layer (PBL), their timelife is higher than ten days [17]. During environmental cycling POPs can be deposited and reemitted several times before reaching a final destinations, this time could be from days to years [18]. Using an average of 26 models, it has been shown that tropospheric ozone has a lifetime around 22 days [19]. It is worth mentioning that three days forward in time, most of the air that comes from the Iberian Peninsula resided over the Mediterranean Sea, with a maximum of residence being found on the Mediterranean coast of the Iberian Peninsula and Northern Africa (Fig. 2a). The sink pattern is elongated eastward, because of the dominant westerly circulation and because the zonal transport is faster than the meridional transport in the extratropical Northern Hemisphere. Similar sink regions can be observed for the sixth day of transport, now covering the entire Mediterranean basin (with maximum centred close to Tunisia) but with a prolonged expansion towards the East, even reaching western China (Fig. 2b). The displacement eastwards continues in the tenth day of transport, reaching most Eastern and Central Asia, with two maxima being observed over the central Mediterranean Sea and over Central Asia (Fig. 2c). Smaller, but noticeable, displacement southwards can be observed over northern Africa. It should be stressed that the upper value of scales used in each panel of Fig. (2) differs substantially, thus the central Asia peak (Fig. 2c) is considerably smaller in magnitude than the western (Fig. 2a) and central (Fig. 2b) Mediterranean peaks.
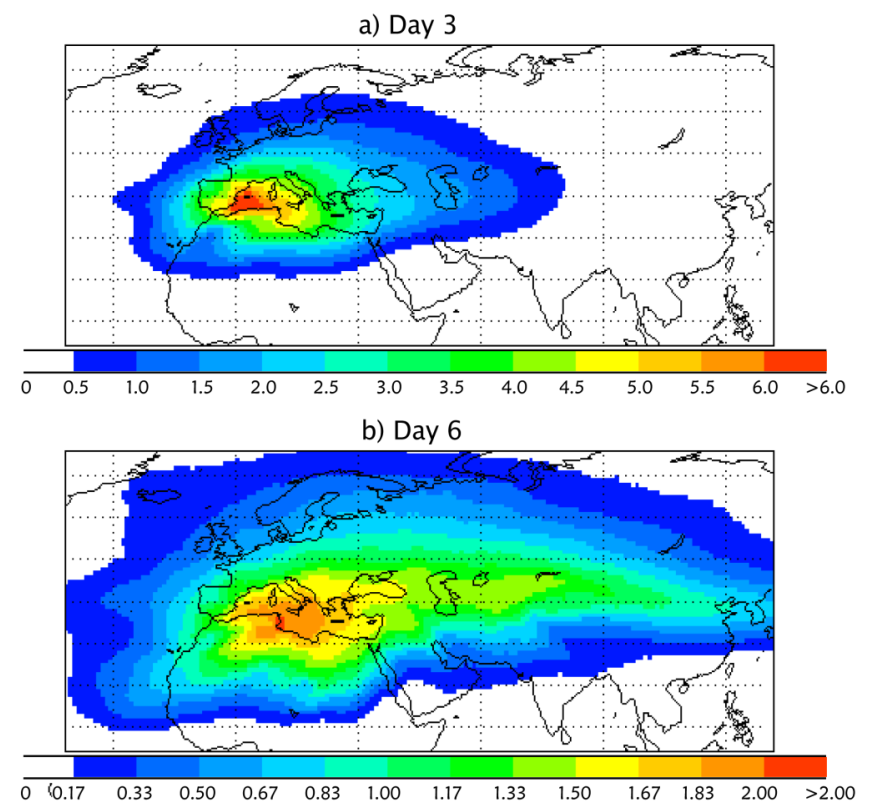

c) Day 10

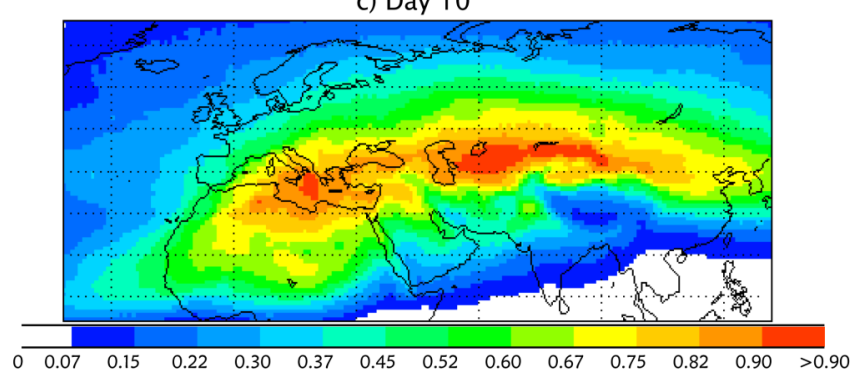

d) From day 3 to 10

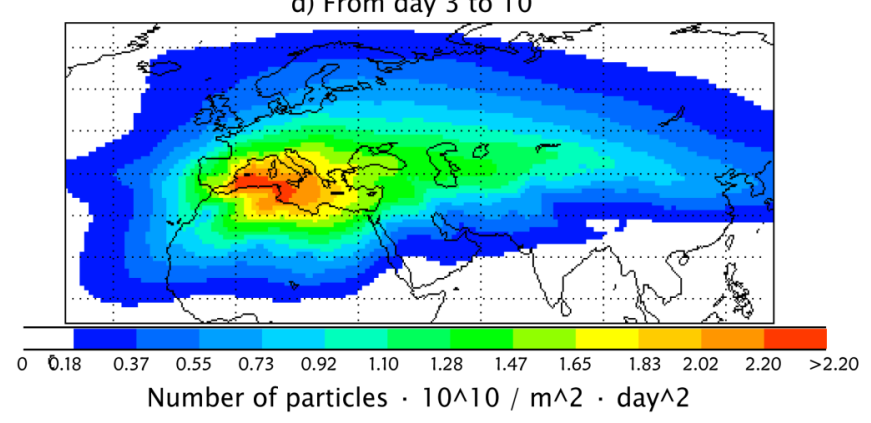

Fig. (2). Annually averaged number of particles from the Iberian Peninsula that reside over a sink area for a) three days forward, b) six days forward, c) ten days forward and d) averaged over days 3 to 10 forward (units are: number of particles $\times 10^{10} \mathrm{~m}^{-2} \mathrm{day}^{-2}$ ).

The average transport shows that the sink of most of the air leaving the Iberian Peninsula in the 3-10 day range corresponds to an elongated region between the Mediterranean and Central Asia, with maximum values centred in the western Mediterranean basin close to the North African coast (Fig. 2d). The finding that the Mediterranean Sea, close to the source region, is the main sink sector of air particles originated in Iberia is in agreement with the atmospheric circulation at the regional scale with dominant westerlies in extratropical latitudes [20]. Furthermore previous studies of pollutant transport reaching eastern Mediterranean have pinpoint Iberia as a source region of pollutants [21] and the 
transport of emissions from European CO column in July 1995 [3]. The local influence (i.e. if we consider the Iberian Peninsula itself as a sink) is small after three days and negligible for both the sixth and tenth days of transport.

Another interesting possibility with this Lagrangian method is the capacity to provide an objective quantification of the number of transported particles towards any predefined region. More precisely it is appealing to evaluate the temporal evolution of the relative weight of the main sinks regions, i.e. the Mediterranean and Central Asia regions.

For this purpose we have quantified the number of particles calculated forwards from the Iberian Peninsula and integrated over four distinct sink regions (Fig. 3). The Mediterranean region was divided in two parts, to evaluate the Northern and Southern Mediterranean areas separately (hereafter NMR and SMR). The other two regions considered correspond to the "local" Iberian Peninsula region (IPR) and the "far" Central Asia region (AR). Fig. (3) shows the limits of these four sink regions (top panel) and depicts the evolution in time of the number of particles (bottom panel, without considering the different areas of each sink region). A simple analysis on Fig. (3) (bottom) puts into evidence that the Mediterranean region is clearly the most important sink up to 3-5 days of transport, being the SMR the principal sink and the NMR the secondary one. From 5 to 10 days of transport the Central Asian region surpasses the number of trajectories bound for both SMR and NMR (when considered in separate). The number of particles delivered over the IPR is less than the supply to SMR, NMR or AR in the range of time analysed here (i.e. 3 to 10 days). For shorter time spans ( 1 to 2 days) IPR is the most important sink, however this is out of the scope of this study that is focused only on potential middle pollution ( 3 to 10 days of transport).

These patterns of particle residence were very robust throughout the year with similar structures appearing when the analysis was performed on a seasonal basis. Fig. (4) shows the variability on the seasonal average number of residing particles (averaged between day 3 and day 10 of transport). The spatial patterns, of favoured particle distribution sink, presents relatively minor differences between the four seasons and also when compared with the annual pattern. These differences are mostly limited to a smaller zonal extension over the eastern Mediterranean Sea and central Asia in spring and summer, i.e. seasons characterised with weaker winds and when the baroclinic activity is lower over the entire Mediterranean basin [22].
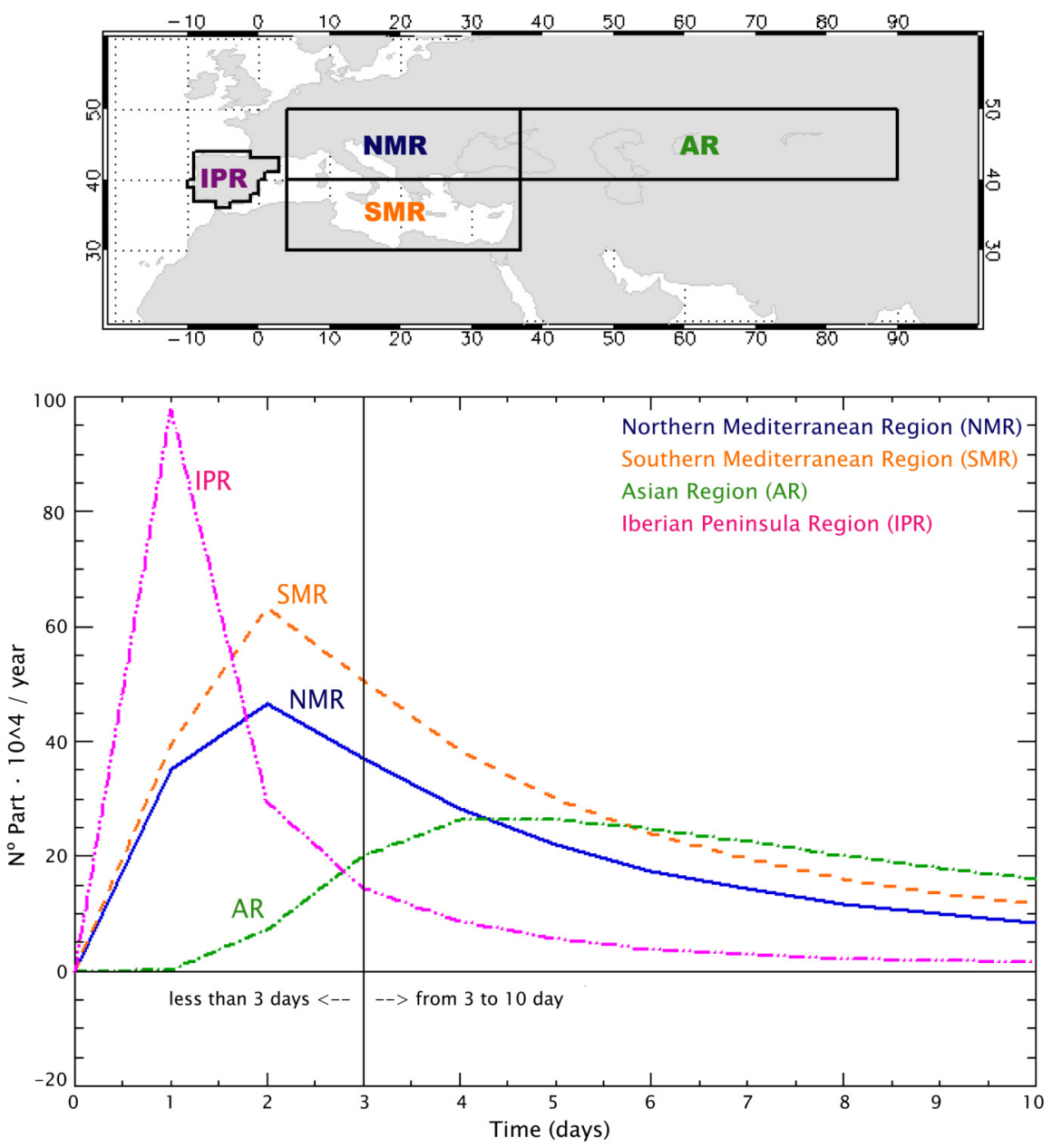

Fig. (3). (Top) Principal sink regions for particles originally located over the Iberian Peninsula area: Northern Mediterranean Region (NMR, blue), Southern Mediterranean Region (SMR, orange), Asian Region (AR, green) and Iberian Peninsula Region (IPR, magenta); (Bottom) absolute values of of particles integrated over the four distinct regions indicated in figure (y-axis scaled by a factor of 10.000). 


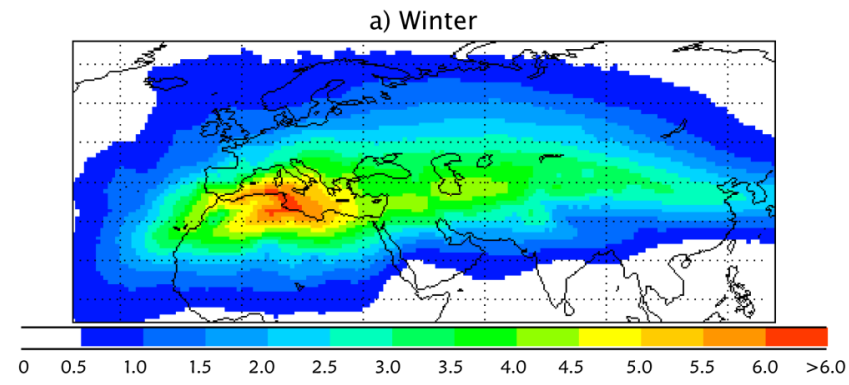

b) Spring

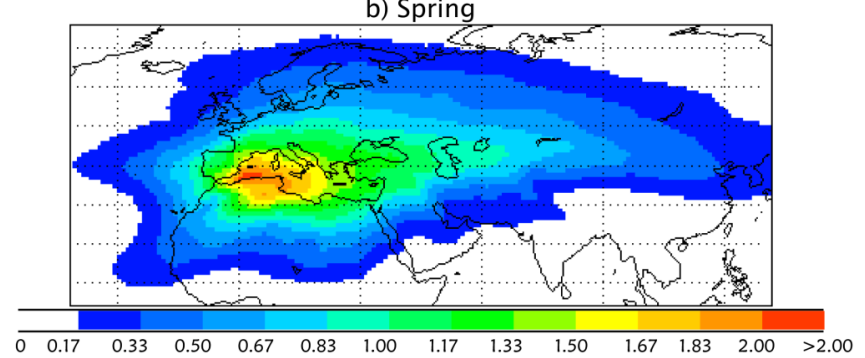

c) Summer

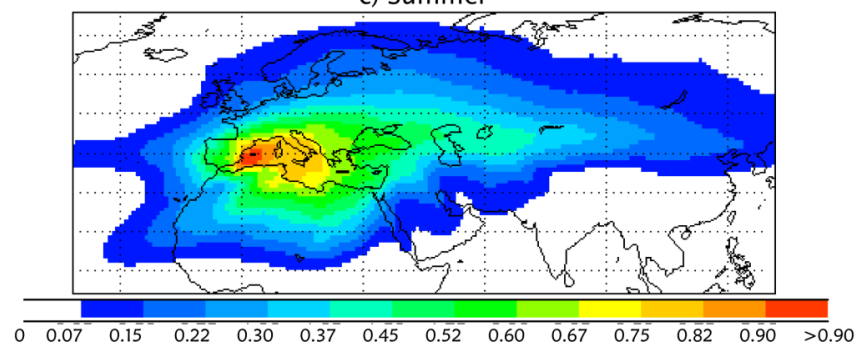

d) Autumn

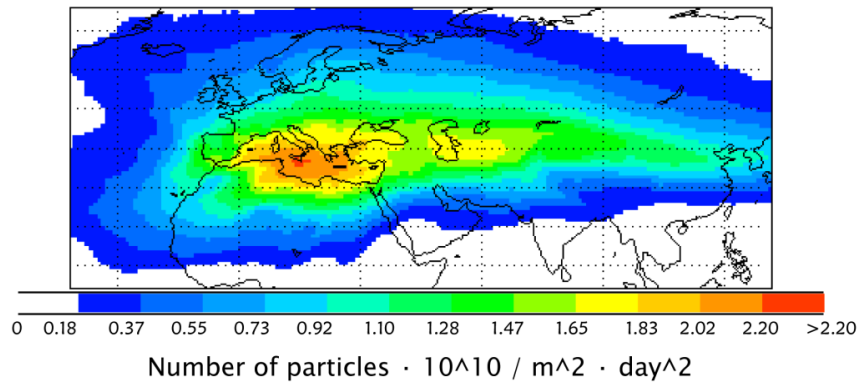

Fig. (4). Seasonally averaged number of particles from the Iberian Peninsula that reside over a sink area averaged over days 3 to 10 back (units are number of particles x $10^{10} \mathrm{~m}^{-2} \mathrm{day}^{-2}$ ).

\section{CONCLUDING REMARKS}

In our view, the present work was particularly instructive and has allowed us to extract the main three conclusions:

The Mediterranean Sea and the Central Asian regions have been found to constitute the main pathways of the air from the Iberian Peninsula within the studied temporal range of 3 to 10 days.

2) The whole Mediterranean area is the dominant sink. However, the relative importance of Mediterranean sink decreases with time after the second day of transport, whereas the Central Asian sink gains relevance from third to fifth day of transport, decreasing (albeit slowly) thereafter.

3) The Mediterranean sink is seasonally-consistent, however the Central Asian sink is sounder during autumn and winter and loses relevance in spring and summer.

These results contribute to understand better (quantitatively) and with a new method previous studies of the intercontinental transport of pollutants and aerosols. Due to the strong anthropogenic-produced aerosols and pollutant emissions in the Western Europe [3]. In this study we have confirmed that Iberia constitutes one of the main potential contributor to the middle-lived pollutants that can be detected over the Mediterranean Sea and also above many central and eastern Mediterranean countries.

\section{ACKNOWLEDGEMENTS}

We thank Andreas Stohl for providing the trajectory data and the Xunta de Galicia and the FCT of Portuguese Ministry of Science (SFRH/BPD/22178/2005) for granting the stays of R. Nieto and L. Gimeno in the "Centro de Geofísica da Univ. de Lisboa" through the programmes "Bolsas para estadias no estranxeiro". We would like also to thank the two anonymous reviewers for their helpful and constructive comments.

\section{REFERENCES}

Fehsenfeld FC, Daum P, Leautch WR, et al. Transport and processings of $\mathrm{O}_{3}$ and $\mathrm{O}_{3}$ precursors over the North Atlantic: An overview of the 1993 North Atlantic Regional Experiment (NARE) summer intensive. J Geophys 1996; 101: 28877-28891.

[2] Hoell JM, Davis DD, Liu SC, et al. The Pacific exploratory mission-west phase B: February-March, 1994. J Geophys Res 1997; 102: 28223-28239.

[3] Duncan BN, Bey I. A modelling study of the export pathways of pollution from Europe: seasonal and interannual variations (19871997). J Geophys Res. 2004; 109: D08301, doi: 10.1029/2003JD0 04079.

[4] Stohl A, Eckhardt S, Forster C, et al. On the pathways and timescales of intercontinental air pollution transport. J Geophys Res 2002; 107: 4684, doi:10.1029/2001JD001396.

[5] Stohl A, Trickl T. A textbook example of long-range transport: Simultaneous observations of ozone maxima of stratospheric and North American origin in the free troposphere over Europe. J Geophys Res 1999; 104: 30445-30462.

[6] Moody JL, Davenport JC, Merill JT, et al. Meteorological mechanisms for transporting O3 over the western North Atlantic Ocean: A case study for August 24-29, 1993. J Geophys Res 1996; 101: 29213-29227.

[7] Parrish DD, Holloway JS, Jakoubek R, et al. Mixing of anthropogenic pollution with stratospheric ozone: A case study from the North Atlantic wintertime troposphere. J Geophys Res 2000; 105: 24363-24374.

[8] Cooper OR, Moody JL, Parrish DD, et al. Trace gas signatures of the airstreams within North Atlantic cyclones: Case studies from the NARE'97 aircraft intensive. J Geophys Res 2001; 106: 54375456.

[9] Cooper OR, Moody JL, Parrish DD, et al. Trace gas composition of midlatitude cyclones over the western North Atlantic Ocean: A conceptual model. J Geophys Res 2002; 107(D7): 4056, doi:10.10 29/2001JD000901

[10] Eckhardt S, Stohl A, Wernli H, et al. A 15-year Climatology of Warm Conveyor Belt. J Climate 2004; 17: 218-237.

[11] Stohl A, Hittenberger M, Wotawa G. Validation of the Lagrangian particle dispersion model FLEXPART against large scale tracer experiment data. Atmos Environ 1998; 32: 4245-4264.

[12] White PW, Ed., IFS documentation. ECMWF Rep Reading, United Kingdom, 2002. Available from: http://www.ecmwf.int.

[13] Nieto R, Gimeno L. Atmospheric transport towards the Iberian Peninsula in the 3- to 10-day range. Sources of middle-lived pollutants and aerosols. ScientificWorldJournal 2006; 6: 1041-1047. doi:10. 1100/tsw.2006.208.

[14] Stohl A, Forster C, Frank A, et al. Technical Note: The Lagrangian particle dispersion model FLEXPART version 6.2. Atmos Chem Phys 2005; 5: 2461-2474. 
[15] Stohl A, Thomson DJ. A density correction for Lagrangian particle dispersion models. Boundary Layer Meteorol 1999; 90: 155-167.

[16] Hedgecock IM, Pirrone N. Chasing quicksilver: modelling the atmospheric lifetime of $\mathrm{Hg}(0)(\mathrm{g})$ in the marine boundary layer at various latitudes. Environ Sci Technol 2004; 38(1): 69-76.

[17] Williams J, de Reus M, Krejci R, et al. Application of the variability-size relationship to atmospheric aerosol studies: estimating aerosol lifetimes and ages. Atmos Chem Phys 2002; 2: 133-145.

[18] Hansen KM, Christensen JH, Brandt J, et al. Modelling atmospheric transport of -hexachlorocyclohexane in the Northern Hemisphere with a -D dynamical model: DEHM-POP. Atmos Chem Phys 2002; 4: 1125-1137.
[19] Stevenson DS, Dentener FJ, Schultz MG, et al. Multimodel ensemble simulations of present-day and near-future tropospheric ozone. J Geophys Res 2006; 111: D08301, doi:10.1029/2005JD006338.

[20] Peixoto JP, Oort AH. Physics of Climate; American Institute of Physics: New York, USA, 1991.

[21] Lelieveld J, Berresheim H, Bormann S, et al. Global air pollution crossroads over the Mediterranean. Science 2002; 298: 794-799.

[22] Trigo IF, Bigg GR, Davies TD. Climatology of cyclogenesis mechanisms in the Mediterranean. Mon Wea Rev 2002; 130: 549569 . 